\title{
Correction
}

\section{Correction: Henderson et al., Long-term Seizure Suppression and Optogenetic Analyses of Synaptic Connectivity in Epileptic Mice with Hippocampal Grafts of GABAergic Interneurons}

In the article "Long-term Seizure Suppression and Optogenetic Analyses of Synaptic Connectivity in Epileptic Mice with Hippocampal Grafts of GABAergic Interneurons” by Katharine W. Henderson, Jyoti Gupta, Stephanie Tagliatela, Elizabeth Litvina, XiaoTing Zheng, Meghan A. Van Zandt, Nicholas Woods, Ethan Grund, Diana Lin, Sara Royston, Yuchio Yanagawa, Gloster B. Aaron, and Janice R. Naegele, which appeared on pages 13492-13504 of the October 1, 2014 issue, several errors were discovered and have been corrected below. These corrections do not affect the main conclusions and interpretations of the paper. They have been corrected in the online PDF version.

\section{Materials and Methods}

On page 13492. 1st column, in the first paragraph of the Material and Methods section, the incorrect doses of drugs were given; the dose of scopolamine methyl bromide was $1.7 \mathrm{mg} / \mathrm{kg}$ and that of pilocarpine hydrochloride was $280 \mathrm{mg} / \mathrm{kg}$. Details about some of the sources and labeling of MGE donor cells were incomplete. Two C57Bl/6N mice studied by video-EEG received transplantations of E13.5 donor MGE cells from CD-1 pregnant dams (Charles River Laboratories). These donor cells were nucleofected with a pCAG-mRFP vector (Bai et al., 2003; vector kindly provided by Joseph LoTurco, University of Connecticut) using the Amaxa mouse neural stem cell nucleofector kit (Lonza) and program C13, with $4-6 \times 10^{4}$ cells per reaction. After nucleofection, the cells were incubated at $37^{\circ} \mathrm{C}$ in transplantation media containing growth factors (as described in the manuscript) for $\sim 12 \mathrm{~h}$ before transplantation. An additional two C57BL/6N mice analyzed by video-EEG received transplantations of E13.5 donor MGE cells from C57BL/6-Tg(CAG-EGFP)1Osb/J pregnant dams (Jackson Laboratories). The RFP-expressing MGE cells were identified after transplantation by immunostaining for RFP (rabbit anti-RFP, 1:1000; Rockland). For all of the other mice in the study, the donor mouse strains and our current protocols for handling the donor cells before transplantation are described correctly in the manuscript.

\section{Acknowledgement}

On page 13492, 1st column, in the acknowledgments section, several contributions were omitted. The correct text is as follows: "This work was supported by the National Institute of Neurological Disorders and Stroke-National Institutes of Health (Grant R15NS072879-01A1), by a Connecticut Stem Cell Established Investigator Grant, and by a Challenge Award from Citizens United for Research in Epilepsy (J.R.N.). We thank Dr. Atsushi Miyawaki of RIKEN Brain Science Institute, Wako, Saitama, Japan, for the pCS2-Venus plasmid; Manolis Kaparakis and Jen Rose, Quantitative Analysis Center at Wesleyan University, for assistance with statistical analyses; and Xu Maisano for assistance with some of the EEG studies.”

\section{Author Contributions}

On page 13492, 1st column, the contributions footnote should have read "Author contributions: J.R.N. and G.B.A. designed research; K.W.H., J.G., S.T., E.L., X.T.Z., M.A.V.Z., N.W., E.G., D.L., S.R., and J.R.N. performed research; K.W.H., J.G., S.T., E.L., X.T.Z., M.A.V.Z., N.W., E.G., D.L., S.R., G.B.A., and J.R.N. analyzed data; Y.Y. provided reagents; K.W.H., J.G., X.T.Z., M.A.V.Z., G.B.A., and J.R.N. wrote the paper."

Figure 4.

On page 13498, the DAPI labels in panels $E$ and $F$ are incorrect. The corrected Figure 4 appears below. The description of these data in the corresponding parts of the text (Fig. 4 legend and Results) is correct. 

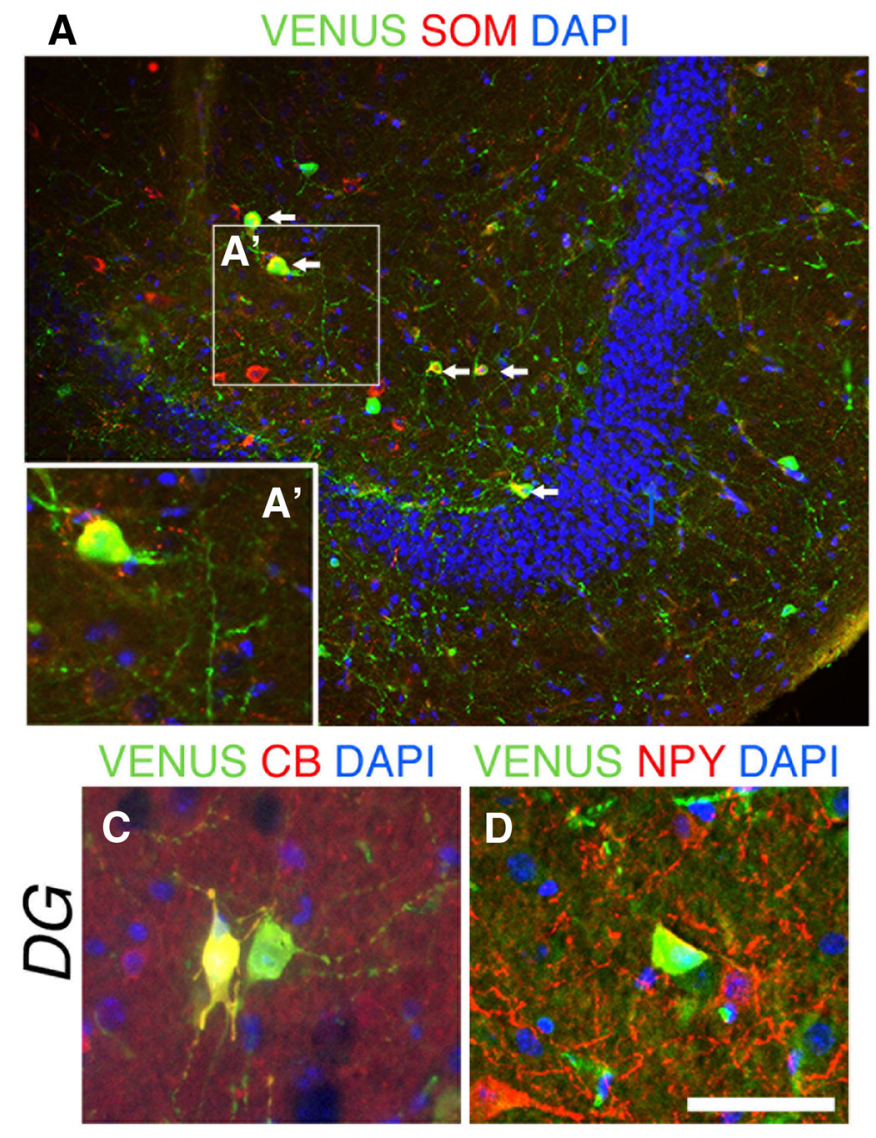

G
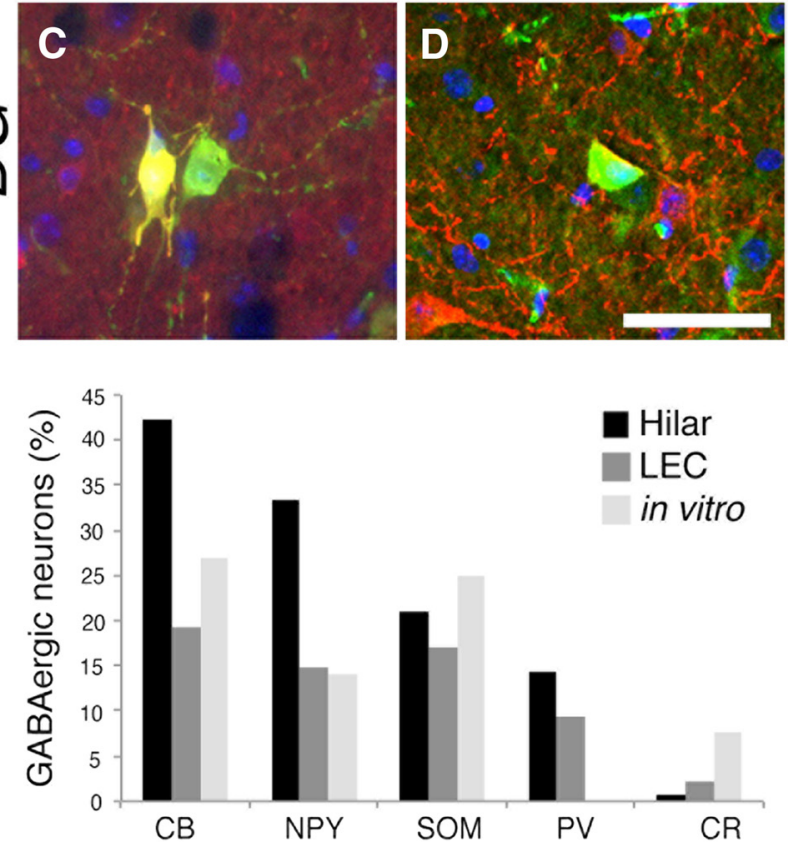

B VENUS PV DAPI
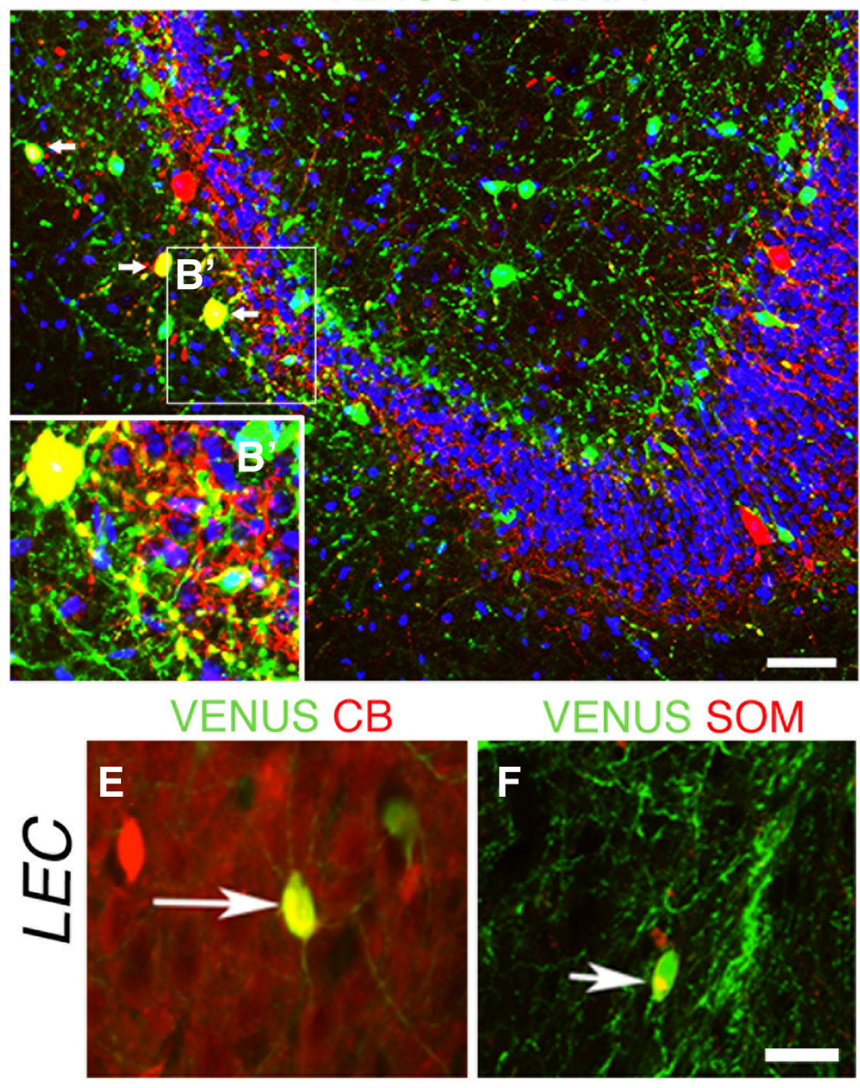

VENUS SOM

H

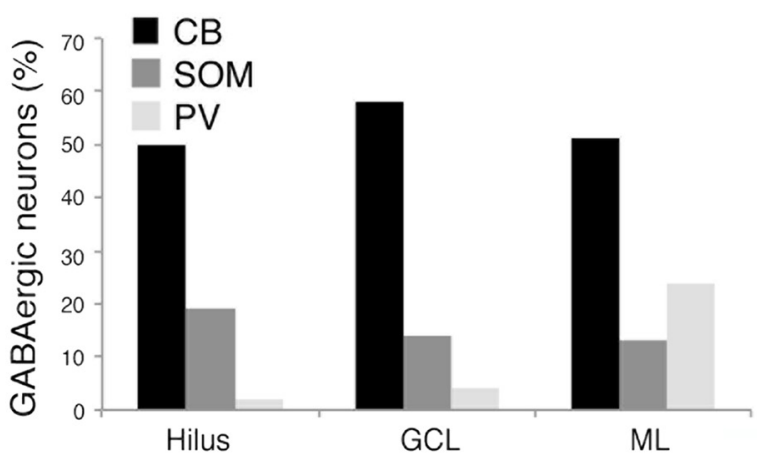

DOI: 10.1523/JNEUROSCI.1275-16.2016 